\title{
Photochemical behaviour of halophenols in aqueous solution
}

\author{
P BOULE $^{a *}$, C RICHARD ${ }^{a}, \mathrm{~K}$ DAVID-OUDJEHANI ${ }^{\mathrm{a}}$ and \\ G GRABNER ${ }^{b}$ \\ ${ }^{\mathrm{a}}$ Laboratoire de Photochimie Moléculaire et Macromoléculaire (URA CNRS 433) \\ Université Blaise Pascal (Clermont-Ferrand) F-63177 Aubière Cedex, France \\ bInstitut für Theoretische Chemie und Strahlenchemie, Universität Wien, \\ Althanstrasse 14 A-1090 Wien, Austria
}

\begin{abstract}
The mechanism of photolysis by direct absorption of chloro-, bromoand fluorophenols ( $\mathrm{XPhOH}$ with $\mathrm{X}=\mathrm{Cl}, \mathrm{Br}$ or $\mathrm{F}$ ) is much more dependent on the position of the halogen than on its nature. In all cases, the first step is a heterolytic $\mathrm{C}-\mathrm{X}$ scission with release of the halogenated acid $\mathrm{HX} .3-\mathrm{XPhOH}$ is almost specifically converted into resorcinol. The anionic form of $2-\mathrm{XPhOH}$ is transformed with a rather high quantum yield into cyclopentadiene carboxylic acids. By nanosecond laser-flash photolysis the first transient detected is a ketene which is converted into fulvene- 6,6 diol and then into the cyclopentadiene carboxylic acids. The phototransformation is about 10 times less efficient from the neutral form and not so specific. The irradiation of 4-XPhOH leads to the formation of a carbene which is the first detected transient. According to the experimental conditions, this transient reacts with oxygen producing a benzoquinone-O-oxide and subsequently $p$-benzoquinone, with water leading to hydroquinone or with another molecule of halophenol producing a halogenodihydroxybiphenyl. It was also observed that 4-chlororesorcinol behaves as both 4-ClPhOH and 2-ClPhOH. Chlorohydroquinone does not react as monohalophenols, the main photoproducts are hydroquinone and chlorobenzoquinone. This reaction is consistent with a radical mechanism. The transformation of halophenols can be sensitized by phenol and in most cases by hydroquinone. The half-life of the triplet state of hydroquinone was evaluated at $0.9 \mu \mathrm{s}$ and the intersystem crossing yield at 0.39 . The sensitization of 3-FPhOH was observed with phenol but not with hydroquinone leading to the conclusion that the energy level of its triplet state lies in the range $310-350 \mathrm{~kJ} \mathrm{~mol}^{-1}$. It is lower than $310 \mathrm{~kJ}$ for the other halophenols studied here.
\end{abstract}

Keywords. Halophenols; photolysis; carbene; 4-chlororesorcinol; hydroquinone.

\section{Introduction}

Halophenols are found as important pollutants of aquatic media and their photodegradation has been a subject of a considerable interest. Since the publication of Omura and Matsuura in 1971 on the direct phototransformation of 4-chlorophenol $^{1}$, many papers were focussed on the photochemical behaviour of halophenols, but the mechanisms of the rëactions were clarified only very recently by laser flash photolysis experiments. The aim of the present work is to update the knowledge in this field.

\footnotetext{
*For correspondence
} 


\section{Methods}

Aqueous solutions of halophenols were irradiated in steady conditions at $254 \mathrm{~nm}$ with a low pressure mercury lamp, at 296 and $313 \mathrm{~nm}$ with a monochromator Bausch and Lomb equipped with a high pressure mercury lamp or at $277 \mathrm{~nm}$ with a monochromator Schoeffel equipped with a xenon lamp.

After irradiation, solutions were analysed by HPLC (column $\mathrm{C}_{18} 250 \mathrm{~nm} \times 4 \mathrm{~mm}$, UV detection). To study the influence of oxygen some solutions were deoxygenated by argon bubbling or degassed by 4 cycles freezing/pumping/thaw. Both methods gave similar results.

A frequency quadrupled Nd-YAG laser (pulse duration $7 \mathrm{~ns}, \lambda_{e x c}=266 \mathrm{~nm}$ ) was used as the light source in transient absorption measurements.

\section{UV spectra}

The pKa of monohalophenols (fluoro, chloro and bromo) lie in the range 8-10. It means that in natural waters these molecules are mainly in molecular form which absorbs at wavelengths shorter than $300 \mathrm{~nm}$ (figure 1). But it is noteworthy that anionic forms absorb at longer wavelengths, i.e. their overlap is more important with sunlight spectrum (figure 2). So the excitation of anionic forms cannot be neglected in environmental conditions. This phenomenon also exists with polyhalogenated phenols. The increase of the halogen number on the ring has a double effect, it introduces a red-shift on the UV spectrum and a decrease in $\mathrm{pKa}$ (roughly $1 p \mathrm{H}$ unit for each halogen). The pKa of pentachlorophenol has been evaluated at 4.7 or 4.8 i.e. similar to the pKa of acetic acid. The maximum of its UV band is located at $300 \mathrm{~nm}$ and $319 \mathrm{~nm}$ with neutral and anionic forms respectively.

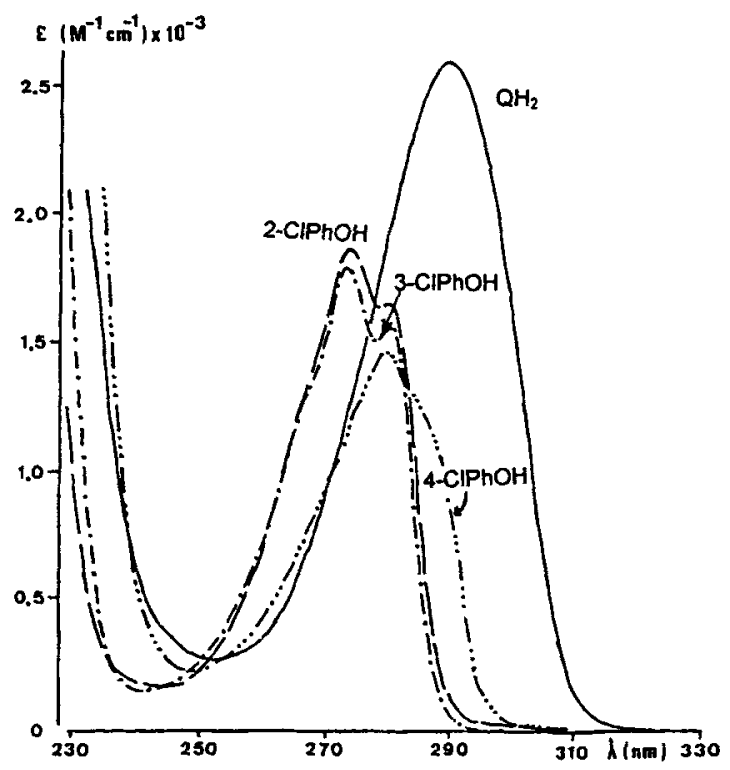

Figure 1. UV spectra of chlorophenols and hydroquinone 


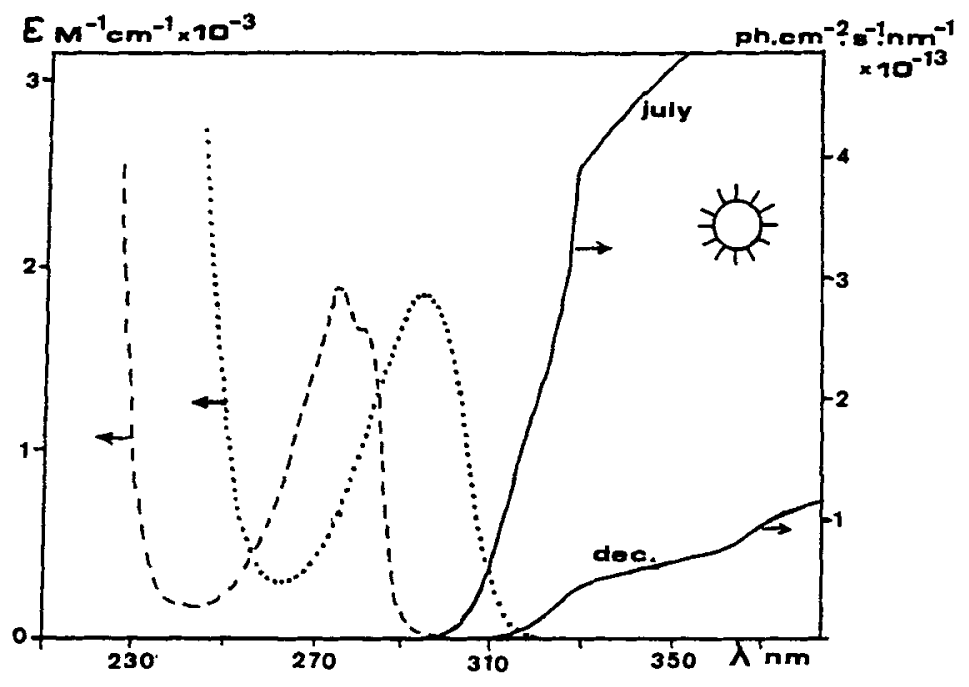

Figure 2. UV spectra of 2- $\mathrm{ClPhOH}(--)$ and 2- $\mathrm{ClPhO}^{-}$(.....) compared to solar spectrum (-) according to R. Franck and W. Klöpffer, Chemosphere 17985 (1988)

\section{Photolysis of 3-halophenols}

When air saturated or deoxygenated solutions of 3-chlorophenol $(3-\mathrm{ClPhOH})$ are irradiated at 254 or $296 \mathrm{~nm}$ the main photoproduct observed is resorcinol which accounts for more than $80 \%$ of the conversion ${ }^{2}$. The same specific reaction was observed with 3-BrPhOH and 3- $\mathrm{FPhOH}^{3}$ and similar one occurs with 3,5-dichlorophenol ${ }^{4}$. A heterolytic mechanism was proposed to explain this specificity and the formation of the halide ion. In the particular case of 3-FPhOH, a homolytic C-F scission is ruled out for energetic reasons since the energy of a photon at $254 \mathrm{~nm}$ $\left(471 \mathrm{~kJ} \mathrm{~mol}^{-1}\right)$ is lower than C-F energy band $\left(523 \mathrm{~kJ} \mathrm{~mol}^{-1}\right)$. Moreover the reaction can be sensitized by phenol (triplet energy level $\approx 350 \mathrm{~kJ} \mathrm{~mol}^{-1}$ ). With $3-\mathrm{ClPhOH}$ a substitution of $\mathrm{Cl}^{-}$by $\mathrm{OH}^{-}$is not consistent with the fact that the reaction is not affected by $p \mathrm{H}$ in the range $0.5-7$. The following mechanism of photohydrolysis was suggested ${ }^{2}$. The lifetimes of intermediates are too short to be detected by nanosecond laser flash photolysis.



<smiles>[R][OH+]c1cccc(O)c1</smiles>

\section{Photolysis of 2-halophenols}

It was reported that the phototransformation of 2-chlorophenol (2- $\mathrm{CIPhOH})$ is much more efficient by irradiation of the anionic form (quantum yield $=0.32)^{5}$ than from the 
molecular form $(\phi \approx 0.030)$. It is also very specific, $2-\mathrm{ClPhOH}$ being quantitatively converted into cyclopentadiene carboxylic acids ${ }^{6}$. These acids cannot be isolated because they dimerize in concentrated solution. But from the structure of dimers it was concluded that two isomeric acids are formed. Chlorine is released as chloride ion.

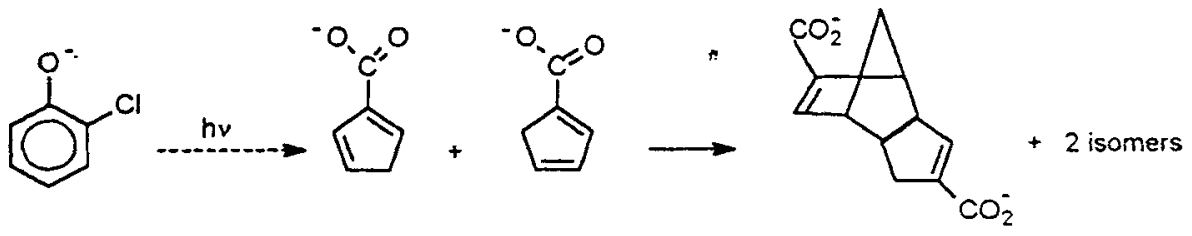

In neutral or acidic solution this reaction competes with the formation of pyrocatechol.

The formation of cyclopentadiene carboxylic acids was also observed with substituted 2-ClPhOH, with 2-BrPhOH and 2-FPhOH ${ }^{3}$. The specificity of the reaction of $2-\mathrm{XPhO}^{-}$is not consistent with a radical mechanism. The intermediate formation of a carbene was suggested but not experimentally proven from the steady state irradiation results.

Recently this mechanism was studied by means of nanosecond laser flash photolysis at $\lambda=266 \mathrm{~nm}$ and transient absorption spectroscopy ${ }^{7}$. The transient spectra obtained upon irradiation of a neutral solution of $2-\mathrm{ClPhOH}\left(5 \times 10^{-4} \mathrm{M}\right)$ are shown in figure 3 . Transient $\underline{1}$ ( $\lambda_{\max }=260 \mathrm{~nm}, \tau=1 \mu \mathrm{s}$ was present at the end of the pulse and subsequently converted into transient $\underline{2}\left(\lambda_{\max }=293 \mathrm{~nm}\right)$. This process was influenced neither by $\mathrm{O}_{2}$ nor by 2-propanol. Similar results were obtained upon excitation of 2-FPhOH and $2-\mathrm{Br} \mathrm{PhOH}$. Transient 1 was assigned to ketene which was produced by photolysis of diazocyclopentadiene in $\mathrm{CO}$ low-temperature matrix and characterized by its UV and IR spectra ${ }^{8}$. Transient $\underline{2}$ was identified as the fulvene-6,6-diol formed by addition of water on the ketene. The reaction behaviour of the fulvene-6,6-diol has been studied as a function of $p \mathrm{H}^{9-10}$. A Wolff rearrangement similar to that observed in the photolysis

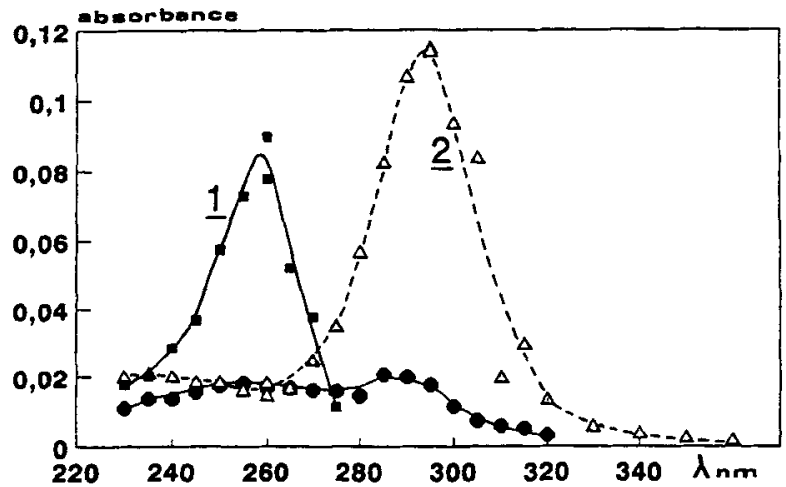

Figure 3. Transient spectra obtained on irradiating an aqueous solution of 2 chlorophenol $5 \times 10^{-4} \mathrm{M}\left(120 \mathrm{~mJ} . \mathrm{cm}^{-2}\right)$

neutral solution, absorbance extrapolated to pulse end $\triangle$ neutral solution, absorbance $8 \mu$ s after pulse end

pH 2 , absorbance $20 \mu$ s after pulse end 


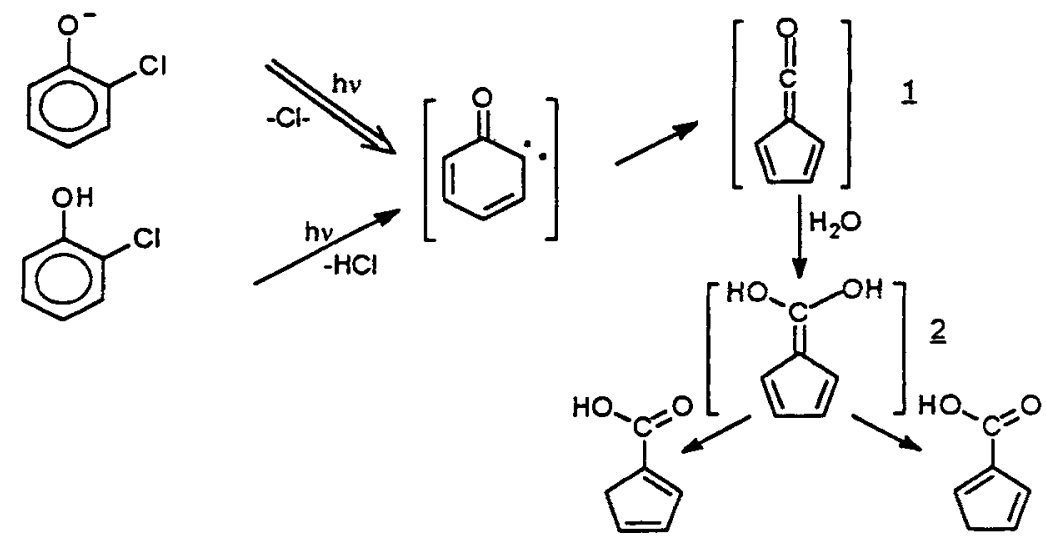

Scheme 1. Mechanism of photolysis of 2-ClPhOH.



Figure 4. Kinetic formation of the main photoproducts in deoxygenated solutions of 4-chlorophenol $\left(2 \times 10^{-4} \mathrm{M}\right)$ irradiated at $296 \mathrm{~nm}$

of $x$-diazoketones ${ }^{11}$ can be proposed to explain the ring contraction (see scheme 1). But, there is no evidence of the involvement of the $\alpha$-ketocarbene in this reaction. Work is in progress for a better understanding of the mechanism of ketene formation.

\section{Photolysis of 4-halophenols}

Among halophenols, 4-chlorophenol (4-ClPHOH) is one of the most studied, probably because it is a pollutant frequently found in waters treated by chlorine. Its photochemical behaviour is complex compared to those of 3-ClPhOH and 2-ClPhOH. Omura and Matsuura ${ }^{1}$ observed the formation of several photoproducts, namely phenol, hydroquinone, 5-chloro-2,4'-dihydroxybiphenyl, 4,4'- and 2,4'-dihydroxybiphenyl in basic concentrated solution. In dilute $\left(\approx 10^{-4} \mathrm{~mol}^{-1}\right)$ air-saturated solution the transformation into benzoquinone is almost quantitative as it was shown by Lipczynska-Kochany ${ }^{12}$. In deoxygenated solution hydroquinone is the major photoproduct, but the formation of 5-chloro-2,4'-dihydroxybiphenyl was also observed ${ }^{13}$. Another hydroxylated compound 2,5,4'-trihydroxybiphenyl appears as a secondary photoproduct (figure 4). In more concentrated solution $\left(2 \times 10^{-3} \mathrm{M}\right)$ the conversion 


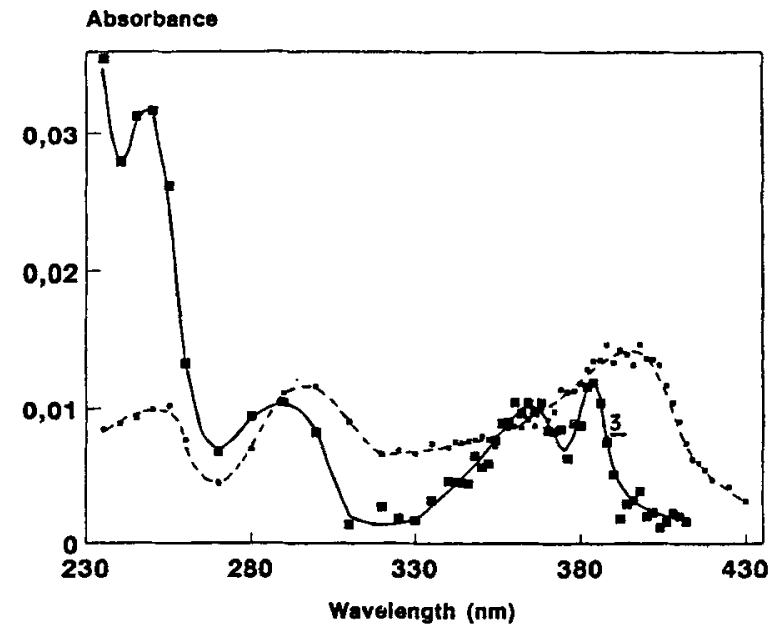

Figure 5. Transient spectra obtained on irradiating an aqueous solution of 4chlorophenol $\left(1.2 \times 10^{-3} \mathrm{M}\right)$

absorbance extrapolated to pulse end (transient 3 )

- absorbance $16 \mu$ s after the pulse

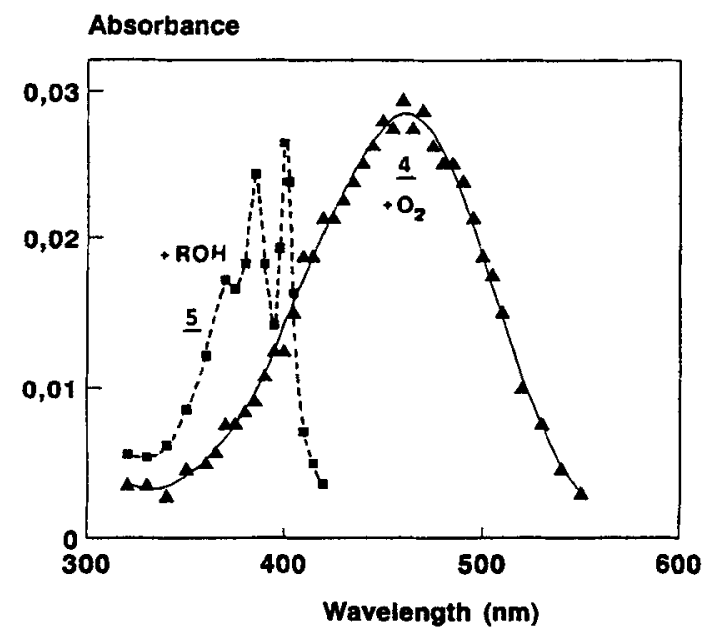

Figure 6. Transient spectra $1 \mu$ s after pulse end in a neutral solution of 4-chlorophenol $\left(1.5 \times 10^{-3} \mathrm{M}\right)$

into benzoquinone is almost quantitative in aerated solution, but 5-chloro-2,4'dihydroxybiphenyl is the main photoproduct initially formed in the absence of oxygen. When solutions are irradiated up to high conversion extent the mixture becomes very complex specially in concentrated solution in which oligomers are formed. It was not possible to understand the mechanism of the reaction from the only steady state irradiations, so laser flash photolysis measurements were carried out to observed transients initially formed ${ }^{14}$.

Irradiation of a neutral deoxygenated solution of 4-ClPhOH lead to the transient spectra shown in figure 5 . At the end of the pulse a two-band feature with maxima at 384 
and $370 \mathrm{~nm}$ was detected (transient 3). $16 \mu$ s after the pulse, these bands have decayed and are replaced by a broad absorption band with a maximum around $400 \mathrm{~nm}$. In oxygen-saturated solutions, transient $\underline{3}$ was observed and converted $1 \mu$ s after the pulse into a broad and intense band centered at $460 \mathrm{~nm}$ (transient 4 , figure 6). When a deoxygenated solution containing a low percentage of 2-propanol was irradiated, transient $\underline{3}$ was transformed into another species exhibiting maxima at 400 and $385 \mathrm{~nm}$ (transient $\underline{5}$, figure 6 ). In solutions containing both oxygen and 2-propanol, transients 4 and $\underline{5}$ were observed simultaneously.

Assignment of all transients was possible with reference to literature data. The characteristic two-band feature of 5 is that of the unsubstituted phenoxyl radical. Transients $\underline{3}$ and $\underline{4}$ were identified by comparison with the results obtained in the photolysis of 4-diazocyclohexa-2,5-dienone ${ }^{15}$. The primary photolytic product is a carbene (4-oxo-cyclohexa-2,5-dienylidene) which has been characterized by matrix isolation spectroscopy. Its absorption spectrum is similar to that of $\underline{3}$. Spectrum of 4 , on the other band, resembles that of $p$-benzoquinone-0-oxide produced by reaction of $\mathrm{O}_{2}$ with the carbene ${ }^{16}$. At last, phenoxyl radical was detected by reaction of the carbene with an $\mathrm{H}$-donor in freon $113^{17}$. These two reactions confirm the assignment of transient $\underline{3}$ to the carbene.

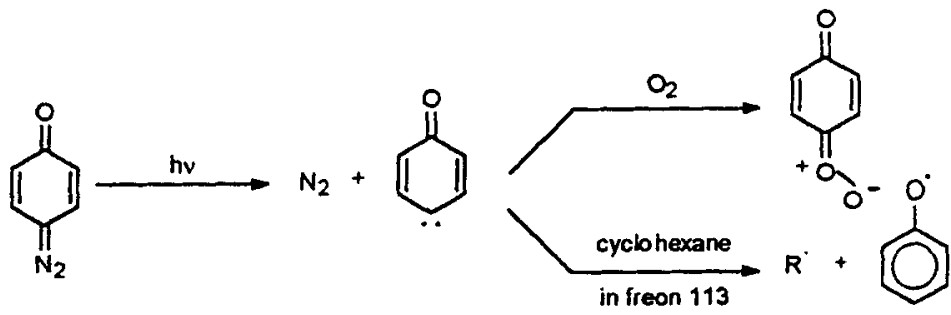

4-diazocyclohexa-2,5-dienone

4-oxo-cyclohexa-2,5-dienylidene

The final phototransformation products are accounted for the reactions of the carbene. Thus the mechanism of the $4-\mathrm{ClPhOH}$ photolysis can be described by scheme 2 . The rate constants of reaction of the carbene with several reactants were measured. Values are given in table 1.

The easy addition of $\mathrm{O}_{2}$ and the high rate constant for reaction with 2-propanol are consistent with the triplet character of the carbene ground state. On the other hand, the rate constant for reaction with water is very low. This reaction probably proceeds by insertion into the $\mathrm{O}-\mathrm{H}$ bond from the thermally populated singlet.

\section{Photolysis of 4-chlororesorcinol}

From a mechanistic point of view, it is of interest to study the photochemistry of molecules which combine the features of ortho- and para-substituted halophenols in terms of substituent position. This is the case for 4-chlororesorcinol (4-ClRes), which has been investigated in aqueous solutions by means of nanosecond transient absorption and product analysis techniques ${ }^{18}$.

From our results it appears that 4-chlororesorcinol (4-ClRes) behaves as both 2-ClPhOH and 4-ClPhOH ${ }^{18}$. In basic solution $(p H=11)$ the photocontraction of the 


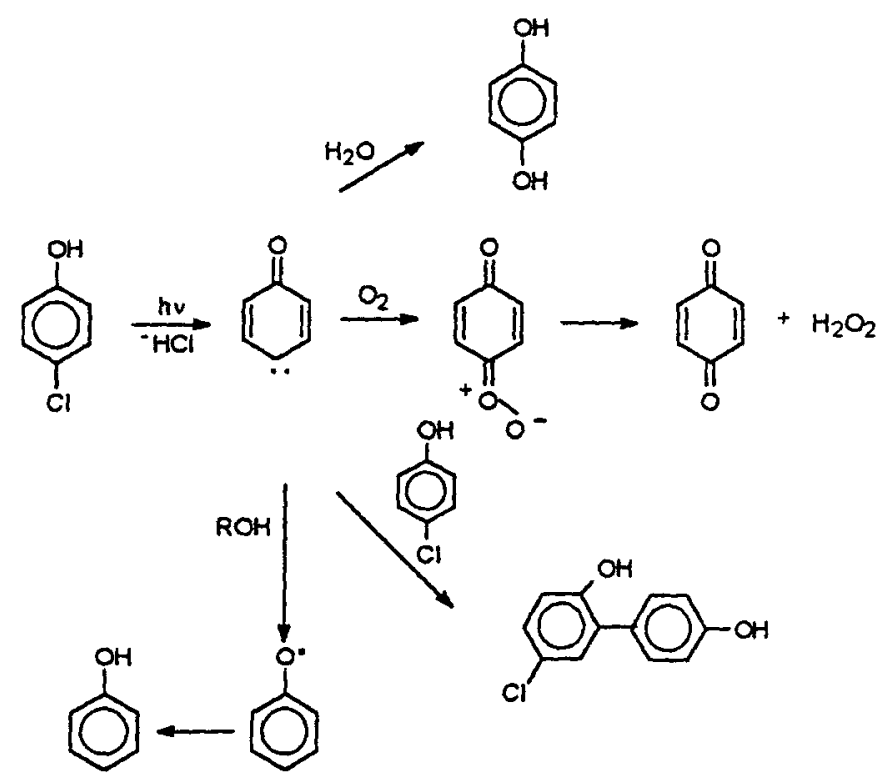

Scheme 2. Mechanism of photolysis of 4-C1PhOH

Table 1. Rate constants of reaction of carbene with various reactants

\begin{tabular}{ll}
\hline 1Reactant & $\mathrm{K}\left(\mathrm{M}^{-1} \cdot \mathrm{s}^{-1}\right)$ \\
\hline $\mathrm{O}_{2}$ & $3.5 \times 10^{9} \mathrm{M}^{-1} \mathrm{~s}^{-1}$ \\
4-ClPhOH & $1.5 \times 10^{8} \mathrm{M}^{-1} \mathrm{~s}^{-1}$ \\
2-propanol & $1.7 \times 10^{7} \mathrm{M}^{-1} \mathrm{~s}^{-1}$ \\
$\mathrm{H}_{2} \mathrm{O}$ & $1.5 \times 10^{3} \mathrm{M}^{-1} \mathrm{~s}^{-1}$ \\
\hline
\end{tabular}

ring is almost quantitative and leads to products $A$ and $B$. In acidic deoxygenated solution $(p \mathrm{H}<6)$ other products are formed such as 1,2,4-trihydroxybenzene and biphenyl derivatives $(C)$.

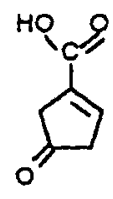

A<smiles>O=C1C=CC(C(=O)O)C1</smiles>

B<smiles>Oc1ccc(-c2cc(O)c(Cl)c(O)c2)cc1O</smiles>

C

Some transient intermediates were detected in this system. The spectra obtained are readily assigned by comparison with the transients obtained from $2-\mathrm{ClPhOH}$ and 4- $\mathrm{ClPhOH}$, both a ketene and a carbene are initially formed. The subsequent reactions of these species are analogous to those obtained for 2- $\mathrm{ClPhOH}$ (formation of a fulvene diol) or 4-ClPhOH (addition of $\mathrm{O}_{2}$, or $\mathrm{H}$ abstraction from an alkanol to form a phenoxyl radical). This reaction behavior is also reflected in the end products as determined by HPLC/NMR. 
<smiles>Oc1ccc(O)c(Cl)c1</smiles><smiles>Oc1ccc(O)c(Cl)c1</smiles>

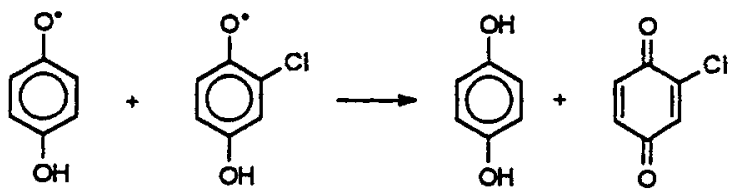

in dilute solution<smiles>CC1=CC(=O)C=CC1=O</smiles>

Scheme 3. Mechanism of photolysis of chlorohydroquinone.

\section{Photolysis of chlorohydroquinone}

Chlorohydroquinone has a special and unexpected behaviour. The main photoproducts observed in air-saturated or deoxygenated solution are hydroquinone and chlorobenzoquinone. In the initial stage of the reaction they are formed in the same proportions and they account for about $80 \%$ of the conversion. The formation of benzoquinone and chlorohydroxybenzoquinone was also observed, the former being favoured by dilution ${ }^{19}$. A radical mechanism is assumed since a transient having a $U V$ spectrum very similar to that of semiquinone and chlorosemiquinone anions was observed in $\mu$ s flash photolysis. When the concentration is about $10^{-3} \mathrm{M}$ the formation of hydroquinone and chlorobenzoquinone can be explained by the mechanism presented in scheme 3. An in cage oxido-reduction of radicals explain the fact that the formation of benzoquinone is favoured in dilute solution, the ratio hydroquinone/ chlorobenzoquinone staying equal to 1 .

The formation of hydroquinone in the photolysis of chlorohydroquinone explains why hydroquinone is formed in the photodegradation of 2-chloro and 3-chlorophenol induced by excitation of nitrate ions since chlorohydroquinone is formed in the first stage of the reaction.

\section{Photosensitization}

It was reported that the triplet state of hydroquinone plays an important role in its photooxidation. Its half-life was evaluated at $0.9 \mu \mathrm{s}$, the intersystem crossing yield $\mathrm{S}_{1} \rightarrow \mathrm{T}_{1}$ at $0.39^{20}$ and its energy level at $311 \mathrm{~kJ} \mathrm{~mol}^{-121}$. Thus hydroquinone is 
expected to have photosensitizing properties. Besides it can be seen on figure 1 that hydroquinone can be selectively excited in solutions containing halophenols in the neutral form. Actually when a deoxygenated solution of 3- $\mathrm{ClPhOH}$ or $3-\mathrm{BrPhOH}$ $\left(2 \times 10^{-4} \mathrm{M}\right)$ and hydroquinone $\left(2 \times 10^{-4} \mathrm{M}\right)$ is irradiated between 300 and $310 \mathrm{~nm}$ the major product is resorcinol ${ }^{3}$. Its formation is attributed to a photosensitization (quantum yield in the range $0 \cdot 1-0 \cdot 18$ ). Resorcinol is not the only photoproduct, 2,5,3'-trihydroxybiphenyl is also formed resulting from a condensation between hydroquinone and halophenol. No formation of resorcinol was observed when hydroquinone was excited in the presence of 3-FPhOH, but the sensitization can be obtained by excitation of phenol at $280 \mathrm{~nm}$. In these conditions the minor direct photolysis of 3-FPhOH was deduced in order to evaluate the quantum yield of the sensitization at about 0.23 . It can be concluded that the photohydrolysis of 3halophenols may occur from the triplet state and that the energy level of the triplet state of $3-\mathrm{FPhOH}$ is in the range $310-350 \mathrm{~kJ} \mathrm{~mol}^{-1}$, values given for hydroquinone ${ }^{21}$ and phenol $^{22}$ respectively.

Photosensitization and formation of adduct can also be observed with 2-halophenols with these differences that the adduct is 2,5,2'-trihydroxybiphenyl and that hydroquinone sensitizes the three substrates 2-BrPhOH, 2-CPPOH and 2-FPhOH ${ }^{23}$. The energy level of the triplet state is thus lower for $2-\mathrm{FPhOH}$ than for 3-FPhOH. This sensitization is an argument to rule out the homolytic scission of C-F bond for energetic reason.

With 4-chlorophenol the sensitization was qualitatively proven but quantitative evaluations are difficult because of the competitive absorptions of sensitizer and substrate.

From the influence of concentration on the yield of photosensitization by hydroquinone and on the yield of formation of trihydroxybiphenyl, it is possible to evaluate both rate constants of sensitization $(\mathrm{ks})$ and formation of adduct $(\mathrm{kr})$ in acidic medium. This influence can be seen on figure 7 given as an example. It can be seen in table 2 that in all cases $\mathrm{ks}>\mathrm{kr}$.

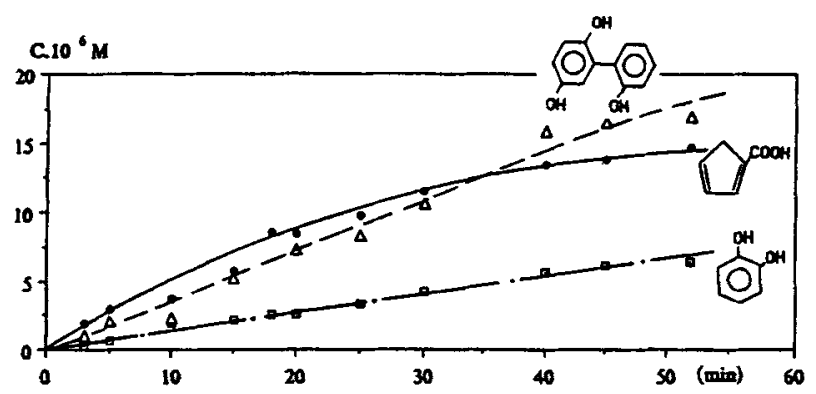

Figure 7. Influence of concentration on the transformation of 2-BrPhOH photosensitized by hydroquinone $[2-\mathrm{Br} \mathrm{PhOH}]=\left[\mathrm{QH}_{2}\right]=2 \times 10^{-4} \mathrm{M}$

Table 2. Values of the rate constants of sensitization by hydroquinone (ks) and of reaction (kr).

$\mathrm{k}\left(\mathrm{M}^{-1} \mathrm{~s}^{-1}\right) \times 10^{-9} 2-\mathrm{BrPhOH} 2-\mathrm{ClPhOH} 2-\mathrm{FPhOH}$ 3-BrPhOH 3-ClPhOH

\begin{tabular}{llllll}
\hline $\mathrm{ks}$ & 4.5 & 1.3 & 0.5 & 6.8 & 2.6 \\
$\mathrm{kr}$ & 1.2 & 0.5 & 0.09 & 0.8 & 0.3 \\
\hline
\end{tabular}


From the sensitization of 3-ClPhOH or 3-FPhOH by phenol it can be deduced that the intersystem crossing yield $S_{1} \rightarrow T_{1}$ of phenol is $\geq 0.5$ and that the lifetime of the tirplet state of phenol is $\geq 1 \mu \mathrm{s}$.

\section{Conclusion}

The photochemical behaviour of halophenols is highly dependent on the position of the halogen on the ring. In most cases the initial reaction is a heterolytic scission of the $C$-X bond. This reaction may occur from the excited triplet state since it can be sensitized. The first step in the photochemical transformation of 4-halophenol is the formation of the carbene 4 oxo-cyclohexa-2, 5-dienylidene. With 2-halophenols the intermediate formation of a ketene was observed. Chlorohydroquinone behaves differently and its phototransformation is tentatively explained by a radical mechanism.

\section{References}

1. Omura K and Matsuura T 1971 Tetrahedron 273101

2. Boule $P$, Guyon C and Lemaire J 1982 Chemosphere 111179

3. David-Oudjehani K and Boule P 1995 New J. Chem. 19199

4. Boule P, Guyon C and Lemaire J 1984 Chemosphere 13603

5. Boule P, Guyon C and Lemaire J 1984 Toxicol. and Environ. Chem. 797

6. Guyon C, Boule P and Lemaire J 1982 Tetrahedron Letters 231581

7. Richard C and Grabner G 1994 Poster presented at XVth IUPAC Symposium on Photochemistry, Prague (Czeck Republic), July

8. Baird M S, Dunkin I R, Hacker N, Poliakoff M and Turner J J 1981 J. Amer. Chem. Soc. 103 5190

9. Urwyler B and Wirz J 1990 Angew. Chem. Int. Ed. Engl. 29790

10. Almstead J I K, Urwyler B and Wirz J 1994 J. Am. Chem. Soc. 116954

11. McMahon R J, Chapman O L, Hayes R A, Hess T C and Krimmer H P 1985 J. Am. Chem. Soc. 1077597

12. Lipczynska-Kochany E 1992 Chemosphere 24911

13. Oudjehani K and Boule P 1992 J. Photochem. Photobiol 68363

14. Grabner G, Richard C and Köhler G 1994 J. Am. Chem. Soc. 11611470

15. Sander W, Bucher G, Reichel F and Cremer D J 1992 J. Am. Chem. Soc. 571346

16. Sander W 1988 J. Org. Chem. 532091

17. Arnold B R, Scaiano J C, Bucher G F and Sander W 1992 J. Org. Chem. 576469

18. Krajnik P, Richard C and Grabner G Poster presented at « Gordon Research Conference on Physical Organic Chemistry 》, Plymouth (USA), July 1995, manuscript in preparation

19. Rossi A, Tournebize A and Boule P 1995 J. Photochem. Photobiol. 85213

20. Boule P, Rossi A, Pilichowski J F and Grabner G1992 New J. of Chem. 161053

21. Vesley G F 1971 J. Phys. Chem. 751775

22. Nauman R V 1949 Thesis, University of California, cf. D. S. McLure, J. Chem. Phys. 17903

23. Oudjehani K and Boule P 1993 New J. Chem. 17567 